\title{
Evidence Based Treatment of Cholera: A Review of Existing Literature
}

\author{
Marzia Lazzerini \\ Institute for Maternal and Child Health IRCCS Burlo Garofolo \\ Italy
}

\section{Introduction}

Cholera outbreaks are reported every year in more than 50 countries worldwide, both in emergency and non-emergency contexts. Every year there are an estimated 3-5 million cholera cases, and 100,000-120,000 deaths. Case fatality rates as high as 50\% have been reported for untreated cholera, but can be reduced to $1 \%$ with rapid and comprehensive treatment. During cholera epidemics the number of cases can rapidly escalate to hundreds of patients in need for immediate therapy, and severe cases will survive only if effectively, timely and safely treated.

This chapter will review the evidence behind the treatment of cholera, providing an up to date description of what we know on cholera treatment from existing scientific literature. The review takes into consideration different aspects of cholera treatment, such as fluids, antibiotics, zinc, and anti-diarrhoeal agents. The types of evidence searched for this umbrella review includes guidelines, systematic reviews and, where needed, clinical trials. Systematic reviews were searched in the Cochrane Library and in MEDLINE (1966 to 2011). In areas of treatment for which no systematic review was retrieved, or when retrieved systematic reviews were over two years old, single studies were searched in the following databases of primary research: the Cochrane Central Register of Controlled Trials (CENTRAL), MEDLINE (1966 to 2011). Guidelines for cholera management were searched in the following databases: MEDLINE (1966 to 2011); World Health Organization (WHO); Center of Diseases and Control (CDC); National Institute for health and Clinical Excellence (NICE); National Guidelines Clearinghouse.

\subsection{When to suspect cholera}

Cholera should be suspected when a child older than 5 years or an adult develops severe dehydration from acute watery diarrhoea (usually with vomiting), or when any patient older than 2 years has acute watery diarrhoea when cholera is known to be occurring in the area. Younger children also develop cholera, but the illness may be difficult to distinguish from other causes of acute watery diarrhoea, especially rotavirus (WHO 2011).

Cholera differs from acute diarrhoea for other causes in three ways:

- it occurs in large epidemics that involve both children and adults; 
- voluminous watery diarrhoea may occur, leading rapidly to severe dehydration with hypovolaemic shock;

- for cases with severe dehydration appropriate antibiotics may shorten the duration of the illness.

\section{Assessment of the severity of dehydration}

The very first step in the treatment of cholera, as well as of other diarrhoeal diseases, is the assessment of the severity of dehydration. The WHO criteria to assess the severity of dehydration are based on the evaluation of few simple signs and symptoms (Table 1).

\begin{tabular}{|c|c|c|c|}
\hline $\begin{array}{l}\text { Look at } \\
\text {-Conditions a } \\
\text {-Eyes b } \\
\text {-Thirst }\end{array}$ & $\begin{array}{l}\text { - Well, alert } \\
\text { - Normal } \\
\text { - Drinks normally, not } \\
\text { thirsty }\end{array}$ & $\begin{array}{l}\text { - Restless, irritable } \\
\text { - Sunken } \\
\text { - Thirsty, drinks } \\
\text { eagerly }\end{array}$ & $\begin{array}{l}\text { - Lethargic or unconscious } \\
\text { - Sunken } \\
\text { - Drinks poorly, or not } \\
\text { able to drink }\end{array}$ \\
\hline $\begin{array}{l}\text { Fell } \\
\text {-Skin pinch } \mathrm{c}\end{array}$ & - Goes back quickly & - Goes back slowly & - Goes back very slowly \\
\hline Decide & $\begin{array}{l}\text { No } \\
\text { Dehydration }\end{array}$ & \begin{tabular}{|l|} 
Some \\
dehydration
\end{tabular} & $\begin{array}{l}\text { Severe } \\
\text { dehydration }\end{array}$ \\
\hline
\end{tabular}

aBeing lethargic and sleepy are not the same. A lethargic child is not simply asleep: the child's mental state is dull and the child cannot be fully awakened; the child may appear to be drifting into unconsciousness.

'In some infants and children, the eyes normally appear somewhat sunken. It is helpful to ask the mother if the child's eyes are normal or more sunken than usual.

cThe skin pinch is less useful in infants or children with marasmus or kwashiorkor, or obese children.

Other signs may be altered in children with severe malnutrition.

Table 1. WHO criteria for the assessment of dehydration in patients with diarrhoea

\section{Treatment of dehydration}

The treatment of patients with dehydration due to cholera follows the same guidelines given for patients with dehydration due to other diarrhoeal diseases, and is substantially consistent among different guidelines (WHO 2011, NICE 2009, WGO 2008, AAP 1996). Here are reported the $\mathrm{WHO}$ guidelines.

\subsection{How to treat severe dehydration}

Patients who develop the typical clinical picture of cholera with severe diarrhoea and rapid fluid loss risk to quickly develop hypovolemic shock, hypoglycemia, coma and seizures and are at risk of dying within a few hours of onset. These patients need to be treated with intravenous fluids, and need to be monitored very closely. The initial intravenous (IV) infusion should be given very rapidly to restore an adequate blood volume, as evidenced by normal blood pressure and a strong radial pulse. Typically, an adult weighing $50 \mathrm{~kg}$ and with severe dehydration would have an estimated fluid deficit of five litres. The first two litres should be given within 30 minutes, and the remainder in the following three hours. 
With cholera, unusually large amounts of oral rehydration salts (ORS) solution may be required to replace large continuing losses of watery stool after dehydration is corrected. The amount of stool lost is greatest in the first 24 hours of illness, being largest in patients who present with severe dehydration. During this period, the average fluid requirement of such patients is $200 \mathrm{ml} / \mathrm{kg}$ of body weight, but some need $350 \mathrm{ml} / \mathrm{kg}$ or more. Patients whose stool losses fall in this range, or are higher, usually require intravenous maintenance therapy using Ringer's Lactate Solution with added potassium chloride. Additional potassium can also be provided by ORS solution as soon as the patient can drink.

After rehydration, patients should be reassessed for signs of dehydration at least every 1-2 hours, and more often if there is profuse ongoing diarrhoea. If signs of dehydration reappear, ORS solution should be given more rapidly. If patients become tired, vomit frequently or develop abdominal distension, ORS solution should be stopped and rehydration should be given IV with Ringer's Lactate Solution (50 ml/kg in three hours), with added potassium chloride. After this it is usually possible to resume treatment with ORS solution.

If possible, suspected cholera patients should be treated under observation until diarrhoea stops, or is infrequent and of small volume. This is especially important for patients who present with severe dehydration. Attention to intake and output is especially important for infants. Food should be restarted as soon as deficits are replaced to minimize the nutritional impact of the illness; refeeding does not affect purging rates or the duration of diarrhoea.

The WHO guidelines for treatment of severe dehydration (Table 2) are based on randomised controlled trials that have shown that severe dehydration due to diarrhoea can be effectively and safety corrected by a rapid infusion over few hours (NICE 2009). Intravenous treatment is recommended also in the rare event of ileus or carbohydrate malabsorption.

\subsubsection{What to do if intravenous therapy is not immediately available}

If IV therapy is not available at the facility, but can be given nearby (i.e. within 30 minutes), send the patient immediately for IV treatment. If the patient can drink, give the care-taker some ORS solution and show her/him how to give it to the patient during the journey.

If IV therapy is not available nearby, health workers who have been trained can give ORS solution by naso-gastric (NG) tube, at a rate of $20 \mathrm{ml} / \mathrm{kg}$ body weight per hour for six hours (total of $120 \mathrm{ml} / \mathrm{kg}$ body weight). If the abdomen becomes swollen, ORS solution should be given more slowly until it becomes less distended. If NG treatment is not possible but the patient can drink, ORS solution should be given by mouth at a rate of $20 \mathrm{ml} / \mathrm{kg}$ body weight per hour for six hours (total of $120 \mathrm{ml} / \mathrm{kg}$ body weight). If the rate is too fast, the patient may vomit repeatedly. In this case, the ORS solution must be given more slowly until vomiting subsides. Patient receiving NG or oral therapy should be reassessed at least every hour. If the signs of dehydration do not improve after three hours, the patient must be taken immediately to the nearest facility where IV therapy is available. If neither NG nor oral therapy is possible, the patient should be taken immediately to the nearest facility where IV or NG therapy is available.

If rehydration progresses satisfactorily, the patient should be reassessed after six hours and a decision on further treatment should made as described above for patients receiving IV therapy. 


\begin{tabular}{|c|c|c|}
\hline & Type of fluid & Quantity \\
\hline $\begin{array}{c}\text { No } \\
\text { dehydration }\end{array}$ & ORS & $\begin{array}{l}\text { Children<2 years: } 50-100 \mathrm{ml} \text {, up to } 500 \mathrm{~mL} / \text { day } \\
\text { Children 2-9 years: } 100-200 \mathrm{ml} \text {, up to } 1000 \mathrm{~mL} / \text { day } \\
\text { Patients }>9 \text { years: As much as wanted, to } 2000 \mathrm{~mL} / \text { day }\end{array}$ \\
\hline $\begin{array}{c}\text { Some } \\
\text { dehydration }\end{array}$ & ORS & $\begin{array}{l}\text { Infants }<4 \text { mos }(<5 \mathrm{~kg}): 200-400 \mathrm{~mL} \\
\text { Infants } 4-11 \mathrm{mos}(5-7.9 \mathrm{~kg}): 400-600 \mathrm{~mL} \\
\text { Children } 1-2 \text { yrs }(8-10.9 \mathrm{~kg}): 600-800 \mathrm{~mL} \\
\text { Children } 2-4 \text { yrs }(11-15.9 \mathrm{~kg}): 800-1200 \mathrm{~mL} \\
\text { Children } 5-14 \text { yrs }(16-29.9 \mathrm{~kg}): 1200-2200 \mathrm{~mL} \\
\text { Patients }>14 \text { yrs (30 kg or more): } 2200-4000 \mathrm{~mL} \\
\text { Over } 4 \text { hours }\end{array}$ \\
\hline $\begin{array}{c}\text { Severe } \\
\text { dehydration }\end{array}$ & $\begin{array}{l}\text { Intravenous } \\
\text { Ringer } \\
\text { Lactate or } \\
\text { Normal } \\
\text { saline } \\
\text { and ORS }\end{array}$ & $\begin{array}{l}\text { Age }<12 \text { months: } 30 \mathrm{~mL} / \mathrm{kg} \text { within } 1 \text { hour*, then } 70 \mathrm{ml} / \mathrm{kg} \\
\text { over } 5 \text { hours } \\
\text { Age }>1 \text { year: } 30 \mathrm{~mL} / \mathrm{kg} \text { within } 30 \mathrm{~min}^{*} \text {, then } 70 \mathrm{ml} / \mathrm{kg} \text { over } 2 \\
\text { and } 1 / 2 \text { hours } \\
{ }^{*} \text { Repeat once if radial pulse is still very weak or not detectable }\end{array}$ \\
\hline \multicolumn{3}{|c|}{$\begin{array}{l}\text { Indications for monitoring the patient } \\
\text { - Reassess the patient every } 1-2 \text { hours and continue hydrating. If hydration is not } \\
\text { improving, give the IV drip more rapidly. } 200 \mathrm{ml} / \mathrm{kg} \text { or more may be needed during } \\
\text { the first } 24 \text { hours of treatment. } \\
\text { - During IV rapid infusion the heart rate and the respiratory rate should decrease. If they } \\
\text { increase, suspect a fluid overload. } \\
\text { - After } 6 \text { hours (infants) or } 3 \text { hours (older patients), perform a full reassessment. Switch } \\
\text { from intravenous to ORS solution if hydration has improved and the patient can drink. }\end{array}$} \\
\hline
\end{tabular}

Table 2. WHO Fluid Replacement Recommendations

\subsubsection{What types of fluids to avoid}

Treating a patient with severe dehydration from infectious diarrhoea with hypotonic solutions such as $5 \%$ dextrose with $1 / 4$ normal saline is unsafe. Severe dehydration usually occurs as a result of bacterial infection (such as cholera), which may lead to greater sodium losses in feces (60 to $110 \mathrm{mmol} / \mathrm{L}$ ). A 1/4 normal saline solution contains sodium (Na) 38.5 $\mathrm{mmol} / \mathrm{L}$, and this does not balance the sodium losses. Intravenous infusion with $5 \%$ dextrose with $1 / 4$ normal saline will thus lead to severe hyponatremia, convulsion, and loss of consciousness. (WGO 2008)

\subsection{How to treat cholera with moderate or mild dehydration}

Patients with cholera but no sign of severe dehydration can be treated with ORS (Table 2). Interestingly, historical events surrounding cholera epidemics have marked the transition to modern rehydration therapy. It was during a cholera epidemic at the time of the Bangladesh Liberation War in 1971 that ORS was proven to be an effective treatment 
for diarrhoea. As medical teams ran out of intravenous fluids to treat the spreading cholera epidemic, the staff was instructed to distribute ORS to the 350,000 people in refugee camps. Over 3,000 patients with cholera were treated. The death rate was only $3.6 \%$ as opposed to the typical 30\% registered with intravenous fluid therapy (Bhattacharya et al. 1994). The physiological basis for ORS use lies in the knowledge that glucose can enhances sodium and water absorption through the sodium-glucose cotransport on intestinal mucosa, even during diarrhoea. Intestinal mucosa is not disrupted during cholera. Moreover, ORS can be given by family members instead of trained staff thus allowing for large populations to be treated even in emergency contexts (Sacks et al. 2004).

This ecological evidence was confirmed by a Cochrane systematic review of seventeen trials in children with gastroenteritis (Hartling et al.2006). The meta-analysis showed no clinically significant differences in outcomes between ORS and intravenous rehydration therapy. It's widely accepted that patients presenting with mild to moderate dehydration secondary to acute gastroenteritis, including cholera, should initially be treated with ORS. However, it must be remembered that mild cases of cholera, if not further investigated, can be misdiagnosed for other diarrhoeal diseases, while according to WHO estimates up to $80 \%$ of people with cholera present only mild diarrhoea. Patients with moderate or mild dehydration need to be followed up to ensure that they do not develop severe dehydration. The patients and their care-takers need to be instructed to come back and seek care should diarrhoea become more severe, or other danger signs appear (inability to drink, weakness and deterioration of the neurological state, blood in the faeces).

\subsubsection{Rice based ORS}

Polymer-based ORS contain whole rice (amylopectins), as in rice-based ORS or rice syrups (maltodextrins), or other sources of polymers such as wheat, sorghum, and maize (high amylase-resistant starch). In these polymer-based solutions, the glucose is slowly released after digestion and is absorbed in the small bowel, enhancing the reabsorption of water and electrolytes secreted into the bowel lumen during diarrhoea.

A 1998 Cochrane Review of rice-based ORS for the treatment of diarrhoea concluded that rice-based ORS significantly reduce the mean 24 hour stool output in adults and children with cholera or cholera-like diarrhoea, but results were inconclusive for infants and children with non-cholera diarrhoea (Fontaine et al. , 1998).

A recent Cochrane review evaluated all polymers (eg rice, wheat, maltodextrins, maize, sorghum, or corn)- based ORS for the treatment of diarrhoea (Gregorio et al., 2009).

- $\quad$ There were fewer unscheduled intravenous infusions in the polymer-based ORS group compared with glucose-based ORS (ORS $<310$ and $<270$ groups combined) (RR 0.75, 95\% CI 0.59 to $0.95 ; 2235$ participants, 19 trials)

- Adults positive for Vibrio cholerae had a shorter duration of diarrhoea with polymer-based ORS than with ORS < 270 (MD -7.11 hours, SD -11.91 to -2.32; 228 participants, 4 trials).

- Wheat-based ORS resulted in lower total stool output in the first 24 hours compared with ORS < 270 (MD-119.85 g/ kg, SD -114.73 to $-124.97 ; 129$ participants, 2 trials).

- $\quad$ Adverse effects were similar for polymer-based ORS and glucose-based ORS. 
WHO and the International Centre for Diarrhoeal Disease research (ICDDR) recommend using rice-based ORS in the treatment of cholera. Rice based-ORS may be available in packets containing pre-cooked rice powder. Alternatively, uncooked rice powder may be added to water, boiled for 5 minutes and allowed to cool before adding salts in the same concentration as in ORS (WHO 2004).

\subsubsection{Low osmolarity ORS}

For several decades, the most widely recommended formulation of ORS contained $90 \mathrm{mmol}$ of sodium and had a total osmolarity of $311 \mathrm{mOsm} / \mathrm{L}$. However, the amount of salts and glucose has always been a subject of debate, and other formulas have been experimented in the field (Table 3).

\begin{tabular}{|l|c|c|c|c|}
\hline & $\begin{array}{c}\text { Standard } \\
\text { ORS }\end{array}$ & \multicolumn{3}{|c|}{$\begin{array}{c}\text { Reduced Osmolarity ORS } \\
\text { (mEq or mmol/1) }\end{array}$} \\
\hline Glucose & 111 & 111 & $75-90$ & 75 \\
\hline Sodium & 90 & 50 & $60-70$ & 75 \\
\hline Chloride & 80 & 40 & $60-70$ & 65 \\
\hline Potassium & 20 & 20 & 20 & 20 \\
\hline Citrate & 10 & 30 & 10 & 10 \\
\hline Osmolarity & 311 & 251 & $210-260$ & 245 \\
\hline
\end{tabular}

Table 3. Composition of standard and reduced osmolarity ORS solutions

Recently, reduced osmolarity ORS (osmolarity decreased to $245 \mathrm{mOsm} / \mathrm{L}$ or lower, reduced amount of sodium) have proved to be superior to high osmolarity ORS in treating acute diarrhoea (Hahn et al, 2001). Based on the greater efficacy of reduced osmolarity ORS solution, especially for children with acute, non-cholera diarrhoea, WHO and UNICEF now recommend that countries use and manufacture reduced osmolarity ORS in place of the previously recommended standard ORS solution (WHO 2004). However, since cholera is associated with significant electrolyte loss especially among children, there are concerns about potential adverse effects (i.e. hyponatraemia) of a reduced osmolarity solution in people with cholera. A Cochrane review set out to answer these questions (Murphy et al., 2004). The review included seven randomised controlled studies (RCTs) on adults and children with acute cholera (confirmed by stool microscopy or stool culture or presumed to be caused by Vibrio cholerae).

- Five trials $(n=616)$ reported on need for unscheduled intravenous infusion and showed no difference between glucose-based reduced osmolarity and standard ORS (RR $0.86,95 \%$ confidence interval 0.66 to 1.12 ).

- Four trials $(n=465)$ showed biochemical hyponatraemia was more common with glucose-based reduced osmolarity ORS (RR 1.67, 95\% CI 1.09 to 2.57), but showed no difference in severe biochemical hyponatraemia between the groups (RR 1.58, 95\% CI 0.62 to 4.04$)$. No trials reported symptomatic hyponatraemia.

In conclusion, in a reasonably large sample of patients with cholera outcomes were similar if treated with reduced osmolarity ORS or standard ORS, apart from asymptomatic hyponatraemia, which was more common with reduced osmolarity ORS. The conclusion of the Cochrane authors is that while it may be easier to administer a single ORS formulation 
worldwide, the potential harms of, and limited evidence on improved efficacy, of reduced osmolarity ORS for patients with cholera should be kept in mind. No further studies have been published to date, and so far the conclusion of the Cochrane authors seems reasonable (Murphy et al., 2004).

\section{Antimicrobial therapy}

Several trials have proved the benefits of antibiotics in treating cholera. Antibiotics reduce the total volume of stool passed, reduce diarrhoea duration, and shorten the period of faecal excretion of $V$. cholerae, thereby reducing cholera transmission. WHO, ICCDR, CDC and several other agencies recommend that all cases of suspected cholera with severe dehydration should receive an oral antimicrobial known to be effective against strains of Vibrio cholerae in the area. WHO guidelines for antibiotic treatment of cholera are reported in Table 4.

\begin{tabular}{|l|l|}
\hline \multicolumn{1}{|c|}{ Antibiotic(s) of choice } & \multicolumn{1}{c|}{ Alternative(s) } \\
\hline Doxycycline & Erythromycin \\
Adults: $300 \mathrm{mg}$ once or & Children: $12.5 \mathrm{mg} / \mathrm{kg}$ \\
& Adults: $250 \mathrm{mg}$ \\
Tetracycline & 4 times a day $\times 3$ days \\
Children: $12.5 \mathrm{mg} / \mathrm{kg}$ & \\
Adults: $500 \mathrm{mg}$ & \\
4 times a day $\times 3$ days & \\
\hline
\end{tabular}

All doses shown are for oral administration. If drugs are not available in liquid form for use in young children, it may be necessary to use tablets and estimate the doses reported in this table. The first dose should be given as soon as vomiting stops, which is usually $4-6$ hours after starting rehydration therapy.

Table 4. WHO guideline of antimicrobial treatment of cholera

Tetracycline-resistant strains of $V$. cholerae $\mathrm{O} 1$ have appeared in many countries. Alternative antimicrobials for treating cholera in children are trimethoprim/sulfamethoxazole (TMPSMX) (5 mg/kg TMP + $25 \mathrm{mg} / \mathrm{kg} \mathrm{SMX,} \mathrm{b.i.d.} \mathrm{[twice} \mathrm{a} \mathrm{day]} \mathrm{for} 3$ days), furazolidone (1.25 $\mathrm{mg} / \mathrm{kg}$, q.i.d. [four times a day ] for 3 days), norfloxacin (WGO 2008) and azitromicin (Saha et al., 2006, Nelson et al., 2010). The choice of antimicrobial should depend on the known resistance/sensitivity pattern of $V$. cholerae in the region. The information may be available from local health institutions. Otherwise, especially in the case of an epidemic, laboratory investigations are required. However, it should be noted that severe dehydration leads to death in cholera, and only rehydration will prevent death. Antibiotics, while useful, are not a lifesaving therapeutic measure, particularly for cholera (ICDDR).

It has been shown that $20-30 \%$ of patients' household contacts develop symptoms of cholera within 10-20 days (Wei et al., 2009). The prevention of transmission is based on hygienic measures (soap, sanitation, potable water). Chemoprophylaxis for the prevention of transmission is debated but not recommended at the moment (Framer et al., 2011). Some evidence from past epidemics in Tanzania and Ecuador suggest that chemoprophylaxis may lead to increased bacterial resistance, without compensatory gains in survival (Weber et al.,1994). 


\section{Zinc}

Zinc deficiency, as well as other micronutrient deficiencies, is wide-spread in low and middle income countries and is thought to have importation health consequences, especially in children. Zinc influences the activity of over 300 enzymes, controlling different functions such as immunity, growth, and development of the nervous system (IZiNCG 2004). There are several different mechanism of action of zinc on acute diarrhoea (Berni Canani et al., 2010). Zinc has a direct effect on ion channels, acting as a potassium-channel blocker of adenosine 3-5-cyclic monophosphate-mediated chlorine secretion (Hoque et al., 2009, Hoque e tal., 2005). Zinc restores mucosal barrier integrity and enterocyte brush-border enzyme activity, and promotes the production of antibodies and circulating lymphocytes against intestinal pathogens, including cholera (Alberts et al., 2003):

A Cochrane review evaluated the efficacy and safety of zinc supplements in the treatment of diarrhoea in children (Lazzerini et al., 2008).

- In acute diarrhoea, zinc shortened the duration of diarrhoea (MD -9.60 h, 95\% CI -18.25 to $-0.96 \mathrm{~h}$; 4242 children, 13 trials), with fewer children with diarrhoea by day three (RR $0.77,95 \%$ CI 0.67 to $0.89 ; 1568$ children, three trials), day five (RR $0.74,95 \%$ CI 0.55 to $0.99 ; 1646$ children, four trials), and day seven (RR $0.82,95 \%$ CI 0.72 to $0.94 ; 5528$ children, 10 trials). The benefit of zinc in children over six months was consistent in subgroup analysis.

- In children under six months, no benefit was demonstrated.

- No trial reported serious adverse events, but vomiting was more common in zinctreated children with acute diarrhoea (RR 1.59, 95\% 1.27 to 1.99; 5189 children, 10 trials).

One study evaluated the efficacy of zinc supplements selectively on cholera. The study enrolled only children and found a $12 \%$ reduction on the duration of diarrhoea compared to control patients and 11\% less stool output (Roy et al., 2008).

Since 2004, zinc supplementation (10-20 mg for 10-14 days) is recommended by WHO, UNICEF and other agencies for all children with diarrhoea,, including cholera (WHO 2004). By continuing zinc supplementation for 10 to 14 days, the zinc lost during diarrhoea is fully replaced and the risk of the child having new episodes of diarrhoea in the following 2 to 3 months is reduced.

\section{Racecadotril}

Racecadotril is an antisecretory drug that inhibits enkephalinase. Enkephalins are endogenous opiate substances which act as neurotransmitters, especially along the digestive tract. By inhibiting enkephalinase, racecadotril reinforces the physiological activity of endogenous enkephalins, which is to elicit intestinal antisecretory activity without affecting intestinal transit time or motility.

To date, only one study has evaluated racecadotril in the treatment of cholera (Alam et al., 2003). The study is a double blind, randomised, placebo controlled clinical trial involving 110 adult male cholera patients who received either racecadotril or placebo in addition to standard cholera treatment. The major outcome measures (stool output, oral rehydration solution (ORS) intake, requirements for unscheduled intravenous fluid infusion, and duration of diarrhoea) were compared between the groups. The study demonstrated that 
racecadotril therapy, although safe, does not provide additional benefit in the treatment of severe cholera in adults.

\section{Loperamide}

No clinical study was retrieved on efficacy and safety of loperamide in cholera. WHO recommends that cholera antidiarrhoeal medicines, such as loperamide, should not be given (WHO 2011).

\section{How to manage a cholera epidemic}

ICCDR is a research centre with vast experience in cholera epidemics. Reported below are the ICCDR guidelines on how to manage a cholera epidemic (ICDDR 2004).

\subsection{The risk associated with a cholera epidemic}

Despite the advances made in treatments that can prevent deaths from cholera, a large number of patients still die each year, particularly during epidemics. Unlike any other diarrhoeal disease, the rate and volume of fluid loss in cholera can threaten life within hours of onset. Cholera deaths can only occur either due to lack of treatment or to inadequate treatment and can be easily averted by prompt and effective rehydration therapy. Deaths are always highest at the beginning of epidemics and are usually associated with areas that have communication difficulties. Access to treatment facilities is often the major problem for cholera patients requiring medical care, particularly in rural areas, where epidemics of the disease are common. It was demonstrated that temporary field treatment centres can be effective in averting deaths during cholera epidemics. The overall aim of makeshift treatment centre, therefore, is to provide quick access to treatment and thus to ensure prevention of deaths. The expected effectiveness of a makeshift treatment centre will depend on sound planning and on efficient running of the centre.

\subsection{When is a temporary treatment centre needed?}

There are no rigid rules to follow in deciding when to set up a makeshift treatment centre and what the ideal location for such a centre would be. However, experience suggests that a temporary treatment centre is usually needed when:

a. a large number of patients with acute watery diarrhoea accompanied with deaths are reported from an area from where transportation to the nearest health facilities is difficult;

b. an epidemic of acute watery diarrhoea involves a large area and is spreading;

c. natural disasters and diarrhoea outbreak occur simultaneously in many areas, such as in post-cyclone epidemics.

\subsection{What would be the best location?}

The specific objective of operating a makeshift treatment centre is to take the emergency health care services to the doorstep of patients who would otherwise be at risk of death during cholera epidemics. Given the limited resources available, providing door-to-door 
health care services in such emergencies is difficult. The optimum benefit of a temporary treatment centre can, therefore, be derived if the treatment centre is set up at a location, which is within easy reach of patients from the affected areas. In rural and remote areas, this is sometimes not an easy task.

Although health posts are ideal for the purpose, they may not be easy to access from the affected areas. Therefore, alternatives such as schools or any other available spaces that can facilitate access to the centre should be selected.

\subsection{Who should be involved?}

The success of a temporary treatment centre depends on the extent to which the treatment facilities are used. Efforts should be made to inform the local population of the physical presence of the treatment centre and its location. Community leaders, village practitioners, and union council members should be involved. The local community leaders and the union council officials are the key persons and should be consulted for providing space for the treatment centre, informing the population and organizing community members to run the treatment centre. The other important persons are the government employed Health Assistants and the village practitioners who are the providers of day-to-day health care at village level. Family members of the patients are to provide nursing care and food for the patient.

\subsection{Resources needed for a temporary treatment centre}

Once the local health care administrators have decided to set up a treatment centre, the next stage is to make plans for the mobilization of resources. While planning to set up a makeshift treatment centre it is important to keep in mind that the effectiveness of a makeshift treatment centre will depend on establishing the centre quickly and moving the logistics easily. One should plan for requirements that are basic and minimum. Due to difficulty of access, transportation of large quantity of supplies to the temporary treatment centre is difficult. Therefore, arrangements should be made to receive required supplies at regular intervals from the permanent source. The basis for estimating resources will depend on the expected patient-load for the treatment centre and the duration of the epidemic. To do this, one should consider these important points: a) at what stage of the local epidemic the treatment centre is to be set up; b) what the magnitude of the epidemic is, in terms of area and population affected. This can be assessed by analyzing the information available locally. In a cholera endemic area such as Bangladesh, seasonal outbreaks usually last 6-8 weeks. However, in newly- infected areas, in refugee camps or in the case of disasterinduced epidemics the period may be longer. The basic and important resources needed are:

a. personnel,

b. rehydration fluids,

c. antibiotics, and

d. a few other essential items such as butterfly needles, etc.

\subsubsection{Personnel, drugs, and supplies needed for a temporary treatment centre}

Experience has shown that during diarrhoea epidemics in rural areas, 10-20 persons per 1000 population may complain of diarrhoea and most of them may have cholera infection. 
Many patients with less severe diarrhoea tend to remain at home. Usually $10 \%$ to $20 \%$ of the patients who seek treatment at the health facilities during epidemics may have severe dehydration. Between 150 and 200 patients may seek treatment in a temporary treatment centre that covers up to two unions (approx. pop. 40,000). Nearly half of the diarrhoea cases seeking treatment don't show signs of dehydration. Between $25 \%$ and $30 \%$ of the cases, however, may show signs of some dehydration and can be, to a large extent, treated with ORS. Approximately, $15 \%$ to $20 \%$ of the cases may need treatment for severe dehydration. They will be needing initial rehydration therapy with IV fluids. Resource requirements were estimated on the basis of a temporary treatment centre expecting to handle at least 100 diarrhoea patients during an epidemic.

\subsection{Assessment of the magnitude and spread of epidemic}

Assessment of the magnitude of epidemic, particularly with relation to the number of persons affected and the geographic distribution of the epidemic is important for planning and for operating the temporary treatment centre. A temporary treatment centre will be less useful if patients fail to use it and when the epidemic moves away from the catchment area. It has been seen that many cholera patients remain at home during epidemics because of the difficulty to access the health facilities or due to milder forms of disease, which escape attention. Many of these patients are inadequately treated or not treated at all. Organizing a local surveillance system to identify cholera patients and to monitor the course of the epidemic is, therefore, essential.

Objectives of the epidemic surveillance:

- Identify cholera patients

- Provide quick treatment

- Assess the magnitude of the epidemic

- Assess the adequacy of available stock of essential supplies

- Identify the pathogen involved and its drug sensitivity patterns

- Set up control measures and monitor progress.

Type of information needed:

- Who are affected and where they are

- Which are the organisms causing the epidemic

- What is the drug sensitivity patterns of the organisms

Source of information:

- Local public health establishments

- Permanent treatment facilities

- Local field health staff

- Private health care providers

- Available records of laboratory investigations

- Community leaders

Box 1. Epidemic surveillance of cholera 


\subsubsection{Identify cholera cases}

One common problem with cholera surveillance is the case definition. The clinical manifestations of cholera cases vary widely. Nevertheless, the use of a standard case definition can facilitate detection of suspect cases. The following definition will assist the field workers to identify cases:

- A patient who is above 2 years of age, suffering from acute watery diarrhoea with rice watery stool, with or without vomiting and with signs of dehydration, should be suspected as a case of cholera during a cholera outbreak.

However, it is still difficult to predict an epidemic and to detect it early in its course because epidemics usually start abruptly, and affect many people within days. Furthermore, the inadequacy of laboratory diagnostic facilities and information systems contributes to delaying both detection and response. Useful indicators for suspecting an outbreak of cholera are: 1) incidence of adult death due to watery diarrhoeal illness of short duration, or 2) increase in hospitalization rates due to acute watery diarrhoea with or without vomiting, particularly in individuals over 2 years of age.

\subsubsection{Collecting illness information}

Information on age, gender, location of the patient, onset of diarrhoea, dehydration status, diagnosis, and treatment administered, should be collected and recorded on a simple form. Information relating to other cases and deaths in the family or in the neighbourhood should also be collected. The mapping of the location of cases is important for the identification of the affected areas and of the source of infection and to monitor the course and spread of the epidemic.

\subsubsection{Laboratory identification of organisms causing an outbreak}

The identification of Vibrio cholerae and their drug sensitivity patterns can only be established by laboratory methods. Laboratory analysis of specimens from suspected cases are, therefore, essential for establishing the cause of an outbreak. However, laboratory tests are expensive. During a suspected cholera epidemic, isolation of $V$. cholerae from a sample of patients' specimens can contribute to establishing the cause of the epidemic. A sample of specimens (Rectal swabs) collected in Carry-Blair medium should be sent to the nearest reference laboratory for culture and to determine antibiotic sensitivity patterns. Furthermore, results of antibiotic sensitivity and resistance patterns from different regions of the country will be useful for the formulation of standard drug protocols. Before collecting rectal swabs one should make sure that the patient did not receive any antibiotics.

\subsection{Control and prevention of local spread of an epidemic}

\subsubsection{Disposal of wastes and disinfecting contaminated material}

It is virtually impossible to provide patients with regular hospital beds in a temporary treatment centre. Contamination of cholera patient surroundings is therefore unavoidable. 
Bedding, including mats, can be disinfected by thorough drying in the sun. After drying, all soiled and contaminated materials should be washed with detergents. A pit-hole in the ground for draining the water used for washing can minimize chances of further contamination. Bleaching powder should be used to disinfect the pit. The pit can also be used to dispose of cholera stool. The floor of the treatment centre can be disinfected by washing, swabbing or sprinkling with bleaching powder solution. Attendants should be advised to wash their hands and clothes thoroughly with detergents.

\subsubsection{Water}

Drinking safe water is a basic requirement. Tubewell water for drinking and for domestic use, if available, should be encouraged. Boiling of water makes it safer. Stored water can also be easily contaminated. Use of narrow-necked itchers for water storage greatly reduces the risk of contamination. Use of bleaching powder solution can disinfect contaminated water. The risk of infection can be further reduced by washing hands with soap and water after defecation and before handling or eating food. Ponds receiving drainage from latrines should not be used to wash utensils or for bathing. Washing stoolcontaminated clothes and bedding of diarrhoea patients can contaminate the surface water (ponds) used for domestic purpose. Drying these materials in the sun before washing can reduce the risk of contamination. Potentially contaminated water can be disinfected with $6 \mathrm{~mL}$ of bleaching powder solution per $10 \mathrm{~L}$ of water $(33 \mathrm{~g}$ of bleaching powder dissolved in one litre of water makes the stock solution). Treated water should be left to sit for at least 30 minutes before use.

\subsubsection{Food}

Many raw foods, such as fish and vegetables, are contaminated with cholera bacteria. Raw food should not be eaten. All foods should be well-cooked and kept covered. Left-overs should be thoroughly re-heated and stale food should be discarded. Food should be eaten as soon as it is cooked or while still hot.

\subsubsection{Washing hands}

Washing hands with water and soap after defecation, before preparing, serving and eating food will reduce the chances of getting infected with the cholera bacteria.

\subsubsection{Health education}

Simple health education messages include: eat freshly cooked food; reheat leftovers and eat while still hot; drink tubewell water or boiled water; wash utensils in clean water and dry them in the sun; wash hands before handling or eating food and after defecation.

\section{Conclusions}

The effective management of cholera is based on few simple rules and procedures, summarized in Box 2. 
1. Assess the severity of dehydration.

2. Replace fluids:

- $\quad$ severe dehydration: IV infusion, replace $10 \%$ of the body weight within 3-6 hr.

- moderate or mild dehydration: standard ORS, rice-based ORS if possible.

3. Monitor the patient:

- repeate the evaluation of the severity of dehydration

- monitor stool output (use cholera cot if possible).

4. Maintain hydration:

- $\quad$ replace continuing fluid losses until diarrhoea stops.

5. Give an oral antibiotic to dehydrated patients as soon as vomiting stops.

- based on the local known resistance/sensitivity pattern

6. Provide food as soon as patient is able to eat (within a few hours).

7. Recognize complications such as hyponatriemia.

8. Give to children zinc supplementation

- dose 10-20 mg for 10-14 days

9. In case of cholera epidemic:

- Aggressive case finding and efficient transport.

- Set up treatment centres for remote areas.

- Start epidemic surveillance.

- $\quad$ Strengthen control and prevention measures.

Box 2. Synthesis of recommendations for the management of cholera

\section{References}

Alam NH, Ashraf H, Khan WA, Karim MM \& Fuchs GJ (2003) Efficacy and tolerability of racecadotril in the treatment of cholera in adults: a double blind, randomised, controlled clinical trial. Gut. 2003;52:1419-23.

Albert MJ, Qadri F, Wahed MA, Ahmed T, Rahman AS, Ahmed F, Bhuiyan NA, Zaman K, Baqui AH, Clemens JD \& Black RE . (2003). Supplementation with zinc, but not vitamin A, improves seroconversion to vibriocidal antibody in children given an oral cholera vaccine. J Infect Dis. 2003 Mar 15;187:909-13.

American Academy of Pediatrics, Provisional Committee on Quality Improvement, Subcommittee on Acute Gastroenteritis. (1996). Practice parameter: the management of acute gastroenteritis in young children. Pediatrics. 1996 ;97:424-35.

Bhattacharya SK. History of development of oral rehydration therapy. Indian J Public Health. 1994;38:39-43. 
Berni Canani R, Buccigrossi V\& Passariello A. (2011). Mechanisms of action of zinc in acute diarrhea. Current Opinion Gastroenterology 2011;1: 8-12.

Farmer P, Almazor CP, Bahnsen ET, Barry D, Bazile J. (2011). Meeting 's Challenge to Haiti and the World: A Joint Statement on Cholera Prevention and Care. PLoS Negl Trop Dis 2011; 5(5): e1145.

Fontaine O, Gore SM \& Pierce NF.1998). Rice-based oral rehydration solution for treating diarrhoea. Cochrane Database of Systematic Reviews 1998, Issue 4. [DOI: 10.1002/ 14651858.CD001264.pub2]

Gregorio GV, Gonzales MLM, Dans LF \& Martinez EG. (2009). Polymer-based oral rehydration solution for treating acute watery diarrhoea. Cochrane Database of Systematic Reviews 2009, Issue 2. Art. No.: CD006519. DOI: 10.1002/14651858.

Hahn S, Kim Y, Garner P. Reduced osmolarity oral rehydration solution for treating dehydration caused by acute diarrhoea in children. Cochrane Database of Systematic Reviews 2002, Issue 1.

Hartling L, Bellemare S, Wiebe N, Russell KF, Klassen TP \& Craig WR. (2006) . Oral versus intravenous rehydration for treating dehydration due to gastroenteritis in children. Cochrane Database of Systematic Reviews 2006, Issue 3. Art. No.: CD004390. DOI:10.1002/14651858.

Hoque KM, Rajendran VM \& Binder HJ. (2005). Zinc inhibits cAMPstimulated Cl secretion via basolateral K-channel blockade in rat ileum. American Journal of Physiology, Gastrointestinal and Liver Physiology 2005;288:956-63.

Hoque KM, Sarker R, Guggino SE \& Tse CM. (2009). A New Insight intoPathophysiological Mechanisms of Zinc in Diarrhea. Annals of the New York Academy of Sciences 2009;1165:279-84.

International Zinc Nutrition Consultative Group (IZiNCG), Hotz C, Brown KH, editors. (2004). Assessment of the risk of zinc deficiency in population and options for its control [Technical Document]. Food and Nutrition Bulletin 2004;25 (1 Suppl 2):94204.

Lazzerini M, Ronfani L (2008). Oral zinc for treating diarrhoea in children. Cochrane Database Syst Rev. 2008;3:CD005436.

Murphy CK, Hahn S \&Volmink J.(2004).Reduced osmolarity oral rehydration solution for treating cholera. Cochrane Database of Systematic Reviews 2004, Issue 4. Art. No.: CD003754. DOI: 10.1002/14651858.

Nelson E, Nelson D, Salam M \& Sack D. (2010). Antibiotics for both moderate and severe cholera. N Engl J Med 2010;364: 5-7.

National Institute for Health and Clinical Excellence (NICE). Diarrhoea and vomiting caused by gastroenteritis: diagnosis, assessment and management in children younger than 5 years. (Clinical guideline 84.) London: NICE, 2009.

Roy SK, Hossain MJ, Khatun W, Chakraborty B, Chowdhury S, Begum A,Mah-e-Muneer S, Shafique S, Khanam M \& Chowdhury R. (2008). Zinc supplementation in children with cholera in Bangladesh: randomised controlled trial. BMJ. 2008 2;336:266-8.

Saha D, Karim MM, Khan WA, Ahmed S \& Salam MA. (2006). Single-dose azithromycin for the treatment of cholera in adults.N Engl J Med 2006;354: 2452-2462. 
Sack DA, Sack RB, Nair GB, Siddique AK. Cholera. Lancet. 2004 Jan 17;363:223-33.

Siddique AK, Asib Nasim SM. (2001). Guidelines for operating makeshift treatment centres in cholera epidemics, international centre for diarrhoeal disease research (ICDDR). Mohakhali, Dhaka-1212, Bangladesh, 2001.

Weber JT, Mintz ED, Canizares R, Semiglia A \& Gomez I. (1994). Epidemic cholera in Ecuador: multidrug-resistance and transmission by water and seafood. Epidemiol Infect 1994;112: 1-11.

Weil AA, Khan AI, Chowdhury F, Larocque RC \& Faruque AS. (2009). Clinical outcomes in household contacts of patients with cholera in Bangladesh. Clin Infect Dis 2009;49: 1473-1479.

WHO. The Treatment of diarrhoea: a manual for physicians and other senior health workers. - 4th rev. Geneva, 2004.

WHO. Cholera. Basic Facts availabl e at http://www.searo.who.int/EN/Section10/Section391.htm

World Gastroenterology Organisation. (2008). WGO practice guideline: acute diarrhea. Munich, Germany: World Gastroenterology Organisation; 2008 Mar. 28 p. 


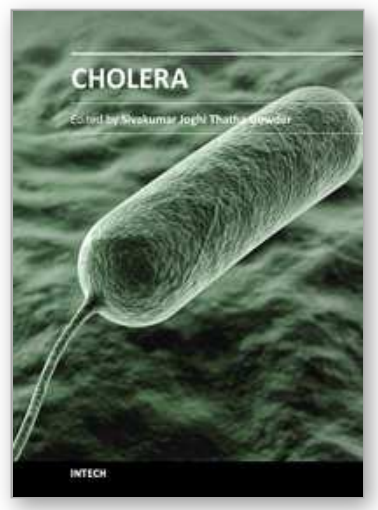

\section{Cholera}

Edited by Dr. Sivakumar Gowder

ISBN 978-953-51-0415-5

Hard cover, 218 pages

Publisher InTech

Published online 28, March, 2012

Published in print edition March, 2012

Cholera, a problem in Third World countries, is a complicated diarrheal disease caused by the bacterium Vibrio cholerae. The latest outbreak in Haiti and surrounding areas in 2010 illustrated that cholera remains a serious threat to public health and safety. With advancements in research, cholera can be prevented and effectively treated. Irrespective of "Military" or "Monetary" power, with one's "Own Power", we can defeat this disease. The book "Cholera" is a valuable resource of power (knowledge) not only for cholera researchers but for anyone interested in promoting the health of people. Experts from different parts of the world have contributed to this important work thereby generating this power. Key features include the history of cholera, geographical distribution of the disease, mode of transmission, Vibrio cholerae activities, characterization of cholera toxin, cholera antagonists and preventive measures.

\section{How to reference}

In order to correctly reference this scholarly work, feel free to copy and paste the following:

Marzia Lazzerini (2012). Evidence Based Treatment of Cholera: A review of Existing Literature, Cholera, Dr. Sivakumar Gowder (Ed.), ISBN: 978-953-51-0415-5, InTech, Available from: http://www.intechopen.com/books/cholera/evidence-based-treatment-of-cholera-

\section{INTECH}

open science | open minds

\section{InTech Europe}

University Campus STeP Ri

Slavka Krautzeka 83/A

51000 Rijeka, Croatia

Phone: +385 (51) 770447

Fax: +385 (51) 686166

www.intechopen.com

\section{InTech China}

Unit 405, Office Block, Hotel Equatorial Shanghai

No.65, Yan An Road (West), Shanghai, 200040, China

中国上海市延安西路65号上海国际贵都大饭店办公楼 405 单元

Phone: +86-21-62489820

Fax: $+86-21-62489821$ 
(C) 2012 The Author(s). Licensee IntechOpen. This is an open access article distributed under the terms of the Creative Commons Attribution 3.0 License, which permits unrestricted use, distribution, and reproduction in any medium, provided the original work is properly cited. 